\title{
Territorial Features and Distribution of Courses Graduate in Physical Therapy: An Analysis in the Environment Virtual Education Ministry
}

\author{
Vera Regina Fernandes da Silva Marães, Leonardo Petrus da Silva Paz, \\ Bruna da Silva Sousa1, Mariana Angélica Peixoto de Souza², Rosana Ferreira Sampaio² \\ ${ }^{1}$ University of Brasilia, Brasília, Brasil \\ ${ }^{2}$ University of Minas Gerais, Minas Gerais, Brasil \\ Email: veraregina@unb.br, vrmaraes@gmail.com
}

Received 27 August 2015; accepted 24 October 2015; published 27 October 2015

Copyright (C) 2015 by authors and Scientific Research Publishing Inc.

This work is licensed under the Creative Commons Attribution International License (CC BY).

http://creativecommons.org/licenses/by/4.0/

\section{(c) (i) Open Access}

\section{Abstract}

The goal of this study was to analyze the territorial distribution and describe the characteristics of undergraduate courses in Physical Therapy in Brazil. Data collection was performed using the virtual system of the Ministry of Education (emec.mec.gov.br) where we sought the following information: name of the institution, state, course load, note the National Examination Performance Students (NEPS), course concept (CC) and other relevant information (steps, extinction, among others). They found 601 Physical Therapy courses. The results show that there is a higher concentration of Physical Therapy courses in the Southeast, the workload and payment time cater to Resolution No. 4 of 6 April 2009 the Ministry of Education (MEC) and also that most courses have satisfactory grades in evaluation of MEC. It is noteworthy that most of the courses are still without concept, like, have an insufficient sample in NEPS or do not complete the evaluation cycle of the National Assessment System of Higher Education in Brazil.

\section{Keywords}

Physical Therapy, Curriculum, Teaching, Graduation, Physical Therapy Education

\section{Introduction}

The Start of Physical Therapy in the world occurs according to Barclay (1994), in 1894 in London, England,

How to cite this paper: Marães, V. R. F. S., Paz, L. P. S., Sousa, B. S., Souza, M. A. P., \& Sampaio, R. F. (2015). Territorial Features and Distribution of Courses Graduate in Physical Therapy: An Analysis in the Environment Virtual Education Ministry. Creative Education, 6, 1908-1913. http://dx.doi.org/10.4236/ce.2015.617196 
with the founding of the Society of Trained Masseuses, the first professional organization of massage class. According to this researcher, two factors contributed to the event: the revival of massage in the 1880s and a scandal involving masseurs in 1894. Doctor Arthur Silva created the first service in Physical Therapy in Brazil in 1884, at Mercy Hospital from Rio de Janeiro.

There is record in the literature that the first Physical Therapy course was created in the United States in 1930. After several studies, the Committee on Education and Publicity of the American Physical Therapy Association published the minimum curriculum and a list of schools qualified in the Journal of the American Medical Association. The curriculum proposed for Physical Therapy courses had a duration of nine months, including 33 hours per week of Physical Therapy instruction, with a total of 1200 hours (Murphy, 1995). In 1951, the first Physical Therapy Course in Brazil in order to train technicians in Physical Therapy was planned and this has been modified over the years both in the nomenclature of the course, as in specialties (Marques \& Sanches, 1994). In the nineteenth century, the therapeutic resources were in use and medical therapy, particularly with electricity and hydrotherapy, thus Physical Therapy was performed only by prescription until after 40 years of its establishment, the profession it was regulated (Pereira \& Almeida, 2006). Currently the undergraduate degree in Physical Therapy presents itself as an ongoing large rise especially in aspects of scientific and economic evidence.

Physical Therapy has two landmarks, which increased their demand and popular recognition, and the time after the Second World War and inversion of the age pyramid respectively. Given the number of individuals with physical sequel (Rebelatto, 1999), and the onset of diseases relating to wear and structural corporal changes (Sanchez, 1984), Physical Therapy presenting developed specialties, thus supplying the patient's home peculiarities. With increasing demand, the emergence of Defective Children Assistance Association (DCAA), the rehabilitation process became more studied and researched internationally, in order to provide higher quality care (Silva \& Brasil, 2008).

However, even with scientific and technological advances, Physical Therapy underwent difficulties for the creation and implementation of its regulatory framework, where for about 40 years the profession was exercised without regulation, and subject to medical prescription, including conducts. However, in 1969 October, it created the Decree-Law No. 938/69, recognizing the importance of professional autonomy and physical therapist and occupational therapist, creating the regional councils of Physical Therapy and Occupational Therapy (CREFITOs) and the federal Council of Physical Therapy and Occupational Therapy (COFFITO) ensuring the rights, duties and physiotherapist conducts (Brasil, 1975).

It is noteworthy that with the evolution of professional regulation, the COFFITO went on to register the number of trained physical therapists and the curriculum guidelines for the formation of professional physiotherapist. Being that with the growing advance of the number of registered physical therapists between the years 1995 and 2005, and the Law of Directives and Bases became clear the importance of a new configuration at graduation of physical therapists future, so that the Ministry of Education-MEC, Ministry of Health-MS, COFFITO, CREFITOs, and Higher Education Institutions (HEIs) gathered for the preparation of proposals for curricular changes of the courses, the National Curriculum Guidelines for Physical Therapy Course being approved by the CNE/ CES 4, DE February 19, 2002.

These changes represent an advancement in methodological quality, and evolution in the specialties in physical therapy. Between the years 1991 and 2004 (after the curriculum change) there was an increase of 606.3\% in the number of undergraduate courses in Physical Therapy in Brazil, influencing and thus increasingly positively on the number of entries in the selection process, expanding well the number of vacancies, enrollment number, and increasing the number of institutions offering the course 10. Studies show that the distribution of Physical Therapy courses in 1991 were minimal in the northern states and the Midwest, and in 2004 all regions recorded growth above $400 \%$, and the Southeast the highest percentage, equivalent to $1.300 \%$. It can be understood that evolution takes place annually progressively.

It is observed that the latest studies on the evolution of Physical Therapy courses comprise only the time the years 1991-2004, and that the curve of participating institutions showed exponential growth (Haddad et al., 2006), with no evidence scientific about the distribution and the characteristics of the graduate programs in Physical Therapy thereafter. Thus, this study aimed to analyze the territorial distribution and describe the characteristics of Physical Therapy in undergraduate courses in Brazil, through the records of the virtual system of the Ministry of Education.

\section{Methods}

Held data collection in the virtual system of the Ministry of Education (emec.mec.gov.br) from May of July 
2015, in two stages. The first was a textual query — cataloging the units after the name of the course; the second stage was a query by the geographical observation made by means of interactive query. The following information of Physical Therapy courses were collected: name of the institution; state; total course hours; note in the National Examination of Student Performance (NEPS) applied every three years to all freshmen and students; concept course (CC) which is the final quality grade given by the Ministry of Education to undergraduate courses of higher education institutions in Brazil (Bittencourt et al., 2008). This final concept is made from an in-person evaluation of courses by experts from the Ministry of Education and can range from one to five; and other relevant information (steps, extinction, among others). The collected data were analyzed (name of the institution, state, total course hours, note in the NEPS and CC) using descriptive statistics with the SPSS (software).

\section{Results}

After collecting and filtering got a total 601 Physical Therapy courses in Brazil. The states of Brazil with highest number of undergraduate Physical Therapy courses are São Paulo (26.79\%), Minas Gerais (10.32\%), Rio de Janeiro (8.32\%) and Bahia (7.15\%) (Table 1).

Table 1. Distribution of Physical Therapy courses by region of Brazil.

\begin{tabular}{|c|c|c|}
\hline Region of Brazil & Number of Physical Therapy courses & Percentage (\%) \\
\hline \multicolumn{3}{|c|}{ North } \\
\hline Acre & 8 & 1.33 \\
\hline Amazonas & 8 & 1.33 \\
\hline Amapá & 4 & 0.66 \\
\hline Pará & 8 & 1.33 \\
\hline Roraima & 1 & 0.17 \\
\hline Rondônia & 7 & 1.16 \\
\hline \multicolumn{3}{|c|}{ Northeast } \\
\hline Alagoas & 8 & 1.33 \\
\hline Bahia & 43 & 7.15 \\
\hline Ceará & 18 & 2.99 \\
\hline Maranhão & 6 & 0.99 \\
\hline Paraíba & 14 & 2.33 \\
\hline Pernambuco & 16 & 2.66 \\
\hline Piauí & 12 & 1.99 \\
\hline Rio Grande do Norte & 8 & 1.33 \\
\hline Sergipe & 6 & 0.99 \\
\hline \multicolumn{3}{|c|}{ Midwest } \\
\hline Distrito Federal & 10 & 1.66 \\
\hline Goiás & 25 & 4.16 \\
\hline Mato Grosso & 9 & 1.50 \\
\hline Mato Grosso do Sul & 9 & 1.50 \\
\hline \multicolumn{3}{|c|}{ Southeast } \\
\hline Espirito Santo & 12 & 1.99 \\
\hline Minas Gerais & 62 & 10.32 \\
\hline São Paulo & 161 & 26.79 \\
\hline Rio de Janeiro & 50 & 8.32 \\
\hline \multicolumn{3}{|c|}{ South } \\
\hline Paraná & 37 & 6.16 \\
\hline Rio Grande do Sul & 35 & 5.82 \\
\hline \multirow[t]{2}{*}{ Santa Catarina } & 24 & 3.99 \\
\hline & 601 & 100 \\
\hline
\end{tabular}


Regarding hours of courses, 98.4\% have higher hourly load equal to 4000 hours and 2.6\% adopt hours less than 4000 hours. Regarding the payment of travel time, 64.6\% have a minimum term 10 semesters as recommended by Resolution No. 4 of 6 April 2009 the Ministry of Education. Regarding the last NEPS notes, 3.8\% of the courses received grade 5; 17.5\% Note 4; 25.3 Note 3; 16.3\% Note 2; 3.2\% Note 1 and 33.9\% are without concept. Regarding the CC, $3.3 \%$ of the courses reached grade $5 ; 21.5 \%$ Note $4 ; 44.8 \%$ note $3 ; 1.7 \%$ Note $2 ; 0.2 \%$ Note 1 and 28.5\% without concept. It is noteworthy that eight courses were accredited and 17 comply with the Program of Incentives to the Restructuring and Strengthening of Higher Education Institutions offered by the federal government.

\section{Discussion}

The number of Physical Therapy courses and consequent interest in the profession has shown exponential growth, which rose from 48 courses in 1991 to 339 in 2004 and 601 in 2015 (Haddad et al., 2006). This represents an increase of almost $177 \%$ since 2004 . A related to this growth factor is the great appreciation of the profession by society, where a degree in Physical Therapy stands out as one of the one of the fastest growing healthcare courses. Another determining factor may be the policy taken by the Federal Government to correct a deficit of higher education in the country. Thus, all areas of knowledge and all professions have undergone expansion process of the number of courses and vacancies (Bispo \& Patrício, 2009; Neves, Raizer, \& Fachinetto, 2007).

The increase in the number of vacancies and Physical Therapy courses occurred in unregulated manner, resulting in unplanned and regulation courses, amidst the stagnation of public higher education institutions and encouraging private institutions. Pereira and Almeida (2006) call attention to two aspects related to this expansion: the privatization of education and the geographical concentration of courses, the latter factor can be seen in the data presented in this study.

In 2003, the distribution of courses by region thus presented: 181 (60.7\%) in the region Southeast; 57 (19.1\%) in the South; 17 (5.8\%) in the Midwest region; 35 (11.7\%) in the Northeast; eight (2.7\%) in the North (Pereira \& Almeida, 2006).

In the present study also shows a concentration of Physical Therapy courses in the Southeast. Evolution in the number of Physical Therapy courses Brazil states follows linearly the Population Estimated number for each state, namely: São Paulo has 44,035,304 inhabitants, Minas Gerais 20,734,097 inhabitants, Rio de Janeiro and 16,461,173 inhabitants Bahia 15,126,371 inhabitants according to the 2014 census (IBGE, 2010).

Another relevant fact is that the regions that have lower concentrations of Physical Therapy courses are the northern regions (5.98\%) of the Midwest (8.82\%) and are the ones with the lowest gross domestic product of the country (GDP), like, the regions that have lower economic activity in the country. GDP is the sum, in monetary terms, of all final goods and services produced in a given region over a given period.

The Physical Therapy undergraduate course in the 60s had as payment time of three years. Only in 1980 began the Physical Therapy Course lasting four years. Despite changes in the payment time and the workload and the great expansion of the physiotherapist playing field, the curriculum still had major distortions, focusing on teaching in sickness and in rehabilitation. After a long work undertaken by representative bodies of the class, Physical Therapy Colleges and several physical therapists, the No. 4 Resolution of 28 February 1983 provides for the minimum curriculum and duration of courses of Physical Therapy and Occupational Therapy. This curriculum focuses on aspects before forgotten, such as the general education disciplines that include Sociology, Anthropology, Psychology, Public Health, Scientific Methodology, as well as emphasizing the specific contents of the area and to state reasons. At this time, the courses had an average 3240 hours (Marques \& Sanchez, 1994; Haddad et al., 2006).

Resolution No. 4 of 6 April 2009 the Ministry of Education provides the minimum hours for the course in Physical Therapy 4000 hours and the National Curriculum Guidelines for the Physical Therapy Course, 2002 (Resolution CNE/CES 4 OF 19 February 2002). It provides that the curriculum for the training of the physiotherapist have to contemplate contents of Biological and Health Sciences, Social and Human Sciences, Biotechnology Knowledge and Skills Physical Therapy. In this study, it is found that 98.4\% of Physical Therapy courses have greater workload equal to 4000 hours and there are still $2.6 \%$ with a workload of less than 4000 hours, which is, not yet meet the National Council Education.

One aspect that evaluates the quality of Physical Therapy education in the country is the National Survey of 
Student Performance (NEPS). According to the Regulatory Ordinance No. 40 of December 12, 2007, Art. 33-D, NEPS, part of the National System of Higher Education Assessment (Sinaes), aims to assess student performance in relation to the contents programmatic curriculum guidelines set out in the relevant undergraduate degree and the skills and competencies in their training. Are assessment tools of NEPS: a proof of knowledge and expertise; one of the student's impressions of questionnaire on the test; one socio-economic survey of the student; and a questionnaire of the course coordinator. Stated students entering and graduating from courses every three years (NEPS Handbook, 2015; Bittencourt et al., 2008). The course receives a note that can range from 1 to 5 , with 1 being the lowest score and 5 is the best result possible in the area, and a footnote 3 is considered satisfactory. Regarding the last NEPS, 3.8\% of Physical Therapy courses received grade 5; 17.5\% Note 4; 25.3 Note 3; 16.3\% Note 2; 3.2\% Note 1 and 33.9\% are without concept. It is noticed that most Physical Therapy courses are no concept this occurs when the course does not meet conditions that may establish the calculation of the same, for example, can cite cases where less than two graduating students or selected entrants participating in the proof. In addition, the courses they have concept, most have grade 4, 3 and 2 . What still worries are those $16.5 \%$ (note 2) and 3.2\% (note 1) that present unsatisfactory grades and need to present to the Ministry of education is a conformity agreement and commitment for improvement in the provision of quality education.

The NEPS data accompanying the results obtained in the course concept which is the final quality grade given by the Ministry of Education to undergraduate courses of higher education institutions in Brazil. This final concept is made from an in-person evaluation of technical courses by the MEC and can range from 1 to 5 . Our findings show that $21.5 \%$ of the courses must note $4 ; 44.8 \%$ had grade $3 ; 1.7 \%$ had grade 2 and $28.5 \%$ are without concept.

The sharp growth of Physical Therapy courses, the increase in the workload for payment of the course, the criteria for assessing the quality of courses may not be economically viable warranty or profession niche markets, but should, before bringing reflect the social needs and consider the contributions of each new course for the transformation of social and epidemiological reality. It also highlights the need for an assessment and further development of the graduate's profile study with a view to cater to what is established in the national curriculum guidelines, with the prospect of structure formation of the physiotherapist from the principles of the NHS and Profile epidemiological of the population (Batista \& Gonçalves, 2011).

\section{Study Limitations}

Differences were found in the consultations held by the Education Ministry of the system. To be held the first step, as the search for the name of the course, the system returned 1084 Physical Therapy courses as a result. However, some courses were listed in about 5 to 7 times. Given this divergence, there was a second stage, as the search for geographical distribution (Brazilian states); this website has returned 143 other courses that were not present in the first stage. After these searches, the researcher also conducted a thorough visual examination to check for possible duplication. It was not approached the graduate's profile Physiotherapist and its compatibility with the needs of the market and society.

\section{Final Thoughts}

The results show that there is a higher concentration of Physical Therapy courses in the Southeast, the workload of most courses meets what is set out in Resolution No. 4 of 6 April 2009 the Ministry of Education and also that most courses have satisfactory grades in the assessment of the Ministry of Education. It is noteworthy that most of the courses are still without concept, as, have an insufficient sample in NEPS or did not complete the evaluation cycle of the National System of Higher Education Evaluation in Brazil.

\section{References}

Batista, K. B. C., \& Gonçalves, O. S. J. (2011). Training of Health Professionals for the NHS: Meaning and Care. Health Society. São Paulo, 20, 884-899.

Barclay, J. (1994). In Good Hands. The History of the Chartered Society of Physiotherapy 1894-1994. Trowbridge: Redwood Books.

Bispo, J., \& Patrício, J. (2009). Training in Physical Therapy in Brazil: Reflections on the Expansion of Education and Training Models. History, Sciences, Health—Manguinhos, Rio de Janeiro, 16, 655-668. 
Bittencourt, H. R., Viali, L., Casartelli, A. O., \& Rodrigues, A. C. M. (2008). An Analysis of the Relationship between the Concepts NEPS and IDD. Studies in Educational Evaluation, 19, 247-262

Brasil (1975). Creation of the Federal Council and the Regional Councils Physiotherapist and Occupational Therapist. Official Diary of the Union, Law n. 6.316, n 242 de 18 de december de 1975, Seção 1, págs. 16.805-16.807.

Haddad, A. E, Pierantoni, C. R., Ristoff, D., Xavier, I. M., Giolo, J., \& Silva, L. B. (2006) The Trajectory of Undergraduate Courses in Health: 1991-2004. Brasília: National Institute of Educational Studies and Research Anísio Teixeira.

IBGE (Brazilian Institute of Geography and Statistics) (2010). Census 2010—Sample Results. Rio de Janeiro, RJ: IBGE.

NEPS Handbook (2015). National Institute of Educational Studies and Research Anísio Teixeira—Ministry of Education.

Marques, A. P., \& Sanches, E. L. (1995) Origin and Evolution of Physical Therapy: Historical and Legal. Physiotherapy Journal of the University of São Paulo, 1, 5-10.

Murphy, W. H. (1995) The Generations: A History of Physical Therapy and the American Physical Therapy Association. Lyme: Greenwich Publishing Group.

Neves, C. E. B., Raizer, L., \& Fachinetto, R. F. (2007) Access, Expansion and Equity in Higher Education: New Challenges for the Brazilian Educational Policy. Sociology, Porto Alegre, 9, 124-157.

Pereira, L. A., \& Almeida, M. (2006). Physiotherapy. In: Oswaldo Cruz Foundation (Ed.), Dynamics of Health Graduations in Brazil: Support for Human Resources Policy (pp. 171-184). Brasília: Ministry of Health.

Rebelatto, J. R. (1999). Physiotherapy in Brazil. São Paulo: Manole.

Rebelatto, J. R. (1969) Regulation of the Profession of Physiotherapist and Occupational Therapist, Law 938, Official Gazette, No. 197, October 14, , Section 1, p. 3658.

Resolution (2002) CNE/CES 4 OF 19 February 2002 Guidelines for National Curiculares Physiotherapy.

Sanchez, E. L. (1984) History of Physical Therapy in Brazil and Worldwide. Brazilian Update Physiotherapy. Ano II. Vol. I. no 03. Magazine R, S Distributors, São Paulo, Mai/Jun.

Silva, C. B., \& Brasil, A. B. S. (2008). Return to Productivity after Rehabilitation Patients Ambulating Head Trauma Victims. Physiotherapy and Research, São Paulo, 15, 6-11. 